\title{
Elecciones y democracia en Guatemala
}

$\mathbb{G}$

n el caso de Guatemala la actualidad del tema electoral es indudable: el próximo mes de noviembre habrá elecciones generales. No obstante, las mismas no tienen más que una importancia relativa en términos de definición de futuro.

Poruna parte está el descrédito en que ha caído el actual gobierno, la debilidad del sistema de partidos y la estrechez de su espectro político e ideológico, con efectosnegativos para la a pertura política -impulsada por elejército-que planteaba el tránsito a la democracia.

Por otra parte, están las contradicciones e insuficiencias que, frente a la complejidad que tiene la confrontación social en Guatemala, muestran los planes con- trainsurgentes, así como la persistencia deposiciones antidemocráticas de importantes sectores de poder-si no es que totales-, las cuales se expresan desde los fraudes electorales como los de 1974,1978 y 1982, hasta la persecución y muerte de losopositores, conlo quese da la paradoja de una apertura política con represión contraria a todo proceso democrático.

Esta situación hunde sus raíces en la contrarrevolución de 1954 y es resultado de la constitución - a partir de entoncesde un dominio político que no quedó sustentado en una base social acorde a los retos que la realidad guatemalteca le planteaba, sobre todo, en términos de resolver las trabas históricas que atenazan a la sociedad. 
SECUENCIA

9

4
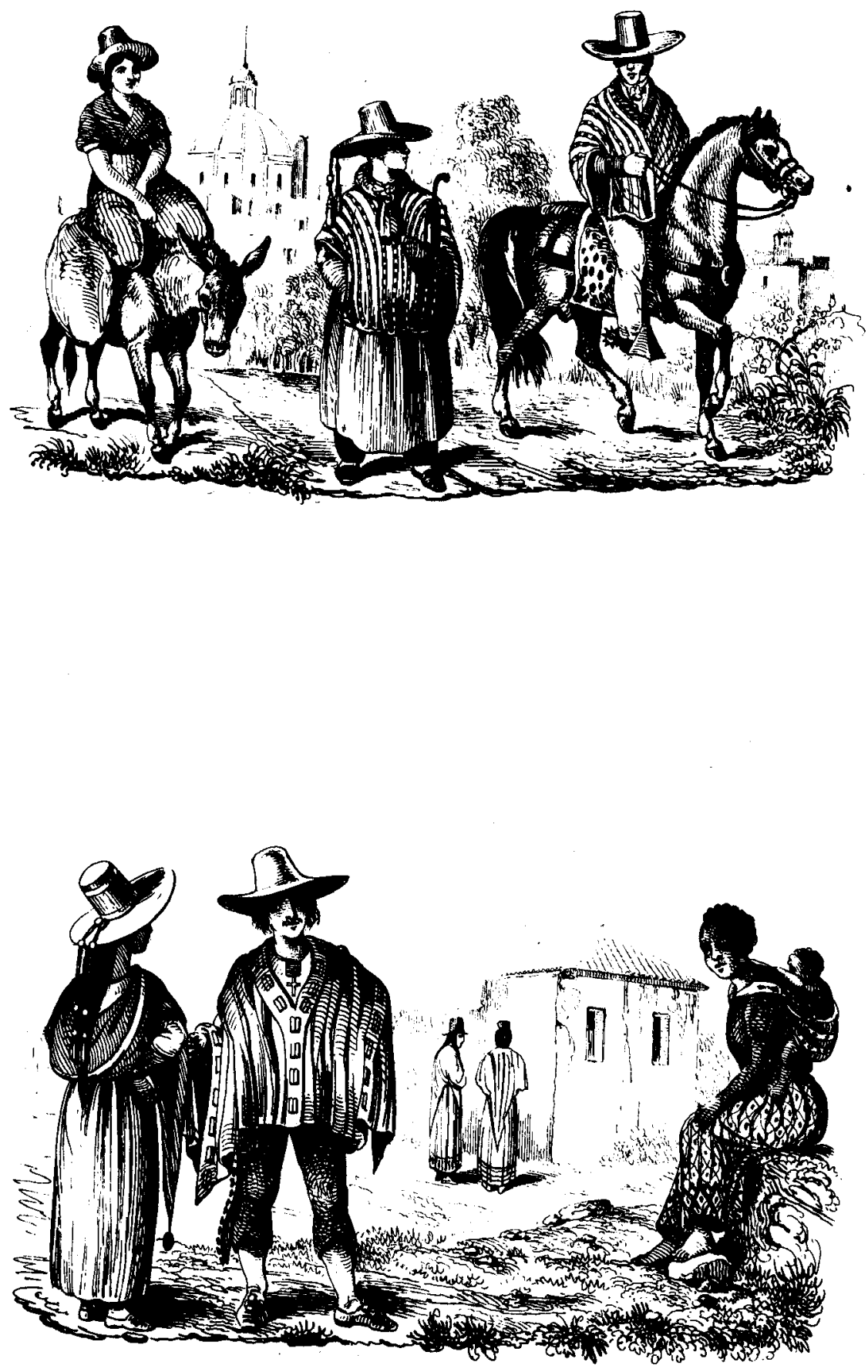
Dichas trabas históricas que afectan las posibilidades de la democracia en Guatemala, se remiten básicamente a:

a) Una base materialsustentada fundamentalmente en la monoexportación agrícola (en un tiempo la cochinilla y desde mediados del siglo pasado el café) sujeta al país -y a la sociedad en su conjunto-a dinámicas que impone el mercado externo, al tiempo que inhibe, bloquea y contrarresta las posibilidades de desarrollo interno. Se trata de una forma de acumulación excluyente y concentradora, depauperadora de las mayorias populares que ahora encuentra límites muy grandes para su reproducción.

b) Un Estadoimposibilitado para ejercer formas de dominación consensuales $y$, por tanto, llamado al uso de la fuerza de manera directa y recurrente.

c) Finalmente, una clase dominante umbilicalmente ligada a los intereses extranjeros -principalmente estadunidenses-, incapaz de formular e impulsar un proyecto nacional que resuelva los límites y los obstáculos que se oponen a su dominación, perpetuando $\mathrm{y}$ acentuando los defectos negativos de los dos factores anteriores.

Estas trabas se conformaron a partir del periodo colonial pero, sobre todo, luego de la independencia de España en 1821; ello, pese al intento revolucionario liberal de 1871 y al proceso revolucionario democrático-popular de 1944-54, de manera que se profundizaron y complicaron al correr del tiempo, anudándose como una sola a partir de 1954; esto dio paso a la confrontación social que ahora existe y a la irrupción del ejército a la cabeza del Estado, a partir del golpe militar de 1963, buscando resolver la situación.

No es mi interés por ahora ni estoy en posibilidad en este momento de desarrollar uno a uno estos aspectos, aunque procuraré relacionarlos con las siguientes cuestiones: 1) La berencia bistórica que se encuentra como sustrato de esta situación; 2) los límites y obstáculos de la actual apertura política impulsada por el alto mando del ejército a partir del golpe de Estado de 1982; 3) las causas de dichos limites yobstáculos que se encuentran -a mi criterio-en la imposibilidad de la contrarrevolución de 1954 para asentar un dominio de clase estable; y 4) algunas consideraciones finales sobre estos problemas y las perspectivas que presenta la lucha por la democracia en Guatemala.

\section{LA HERENCIA HISTÓRICA}

En Guatemala existe una polarización social profunda que descansa en la concentración extrema y prácticamente inalterable de la tierra -en un país esencialmente agrícola- y en la marcada desigualdad de los ingresos. Dicha polarización se manifiesta actualmente en la confrontación social por la que atraviesa el país y se ve agravada -como veremos más adelante- por los efectos negativos que sobre el conjunto de la sociedad tiene la actual reconversión capitalista mundial, dada la dependencia extrema del paîs respecto al extranjero.

A mi criterio, estas condiciones negativas para el desarrollo de la sociedad trataron de ser resueltas por la revolución de octubre de 1944, pero tal posibilidad fue cercenada con la intervención norteamericana y la conformación deuna alianza reaccionaria entre el capital local y extranjero, entre terratenientes, burguesía y los principales mandos del ejército en torno al proyecto contrarrevolucionario. El carácter antipatriótico y antipopular de este proyecto determinó la imposibilidad de legitimar desde su 
inicio al régimen así surgido y tampoco se logró esto en el proceso, fundamentalmente por la inexistencia de canales e instrumentos de negociación mediación entre el Estado y la sociedad civil. Por ello, al dificultarse el control de los sectores subalternos -e impedir su emergencia política-, junto a los obstáculos impuestos a la conformación de posiciones centristas, se da la perpetuación del uso estatal de la fuerza.

A partir de 1954, el régimen pretendió resolver el conflicto social sin tocar lo esencial del sistema dominante, básicamente, sin impulsar la reforma agraria. El problema es que, pese a los esfuerzos hechos, las condiciones estructurales y superestructurales que pretende conservar le son adversas. Por una parte, debido a la rigidez y límites de una economía y de una clase dominante basadas en la exportación de un sólo producto (el café), y por la otra, en razón a la presencia de nuevos sujetos políticos que se vienen fortaleciendo dentro de la sociedad, principal mente desde 1944, básicamente, los trabajadores asalariados del campo y de la ciudad, el campesinado pobre y los pueblos indígenas, constituidos ya en importantes fuerzas políticas emergentes poco dispuestas a aceptar la dominación que se les impone.

A partir de 1954, pese a la incorporación de nuevas actividades productivas al conjunto ya existente (industriales y extractivas, básicamente, aunque también de diversificación agrícola y pecuaria) y de nuevos sujetos sociales a las distintas fracciones de la burguesía, ello ocurre sin alterar la matriz económicosocial fundamental, estructurada principalmente en torno a las exportaciones de café, la subsistencia del eje latifundio-minifundio y el elevado peso de la producción agrícola sobre la economía.

Esta situación determinó la forma- ción, a mediados de los años setenta, de una franja monopólica de capital -la gran burguesía-, con carácter múltiple (agrario, comercial, industrial y financiero), cuya base principal de sustentación son las agroexportaciones. Dicha burguesía se encuentra asociada al capital transnacional bajo la forma de grupos económicos que lo mismo invierten en uno que en otro sector de la economía, aunque volcados en lo fundamental al mercado externo y, por tanto, poco interesados y necesitados del impulso de un "proyecto nacional" o, al menos, de un mercado interno fuerte y en expansión. Además, se trata de una clase que en su práctica cotidiana se muestra incapaz de concebir y aplicar procesos de mediación política y está poco dispuesta a ceder sus privilegios aunque sea en mínima parte.

Así, resulta que los intereses y las necesidades de las fuerzas políticas emergentes no tienen cabida dentro de dicha estructura y, por ello, es inevitable su choque con la clase dominante y con quienes la sostienen. Por eso se mantiene, reproduce y fortalece el aparato estatal dirigido a la violencia y se neutralizan los efectos políticos que podrían tener los intentos desarrollistas que, a partir del golpe de Estado de 1963, impulsa el ejército.

Se crea así un círculo vicioso, acentuado por la dependencia frente a EU, que termina por provocar que el Estado - a pesar de que se asentó en una economía en expansión entre 1950 y 1980se encuentre incapacitado para darle flexibilidad a la dominación de clase.

Por eso, esta situación se muestra irresoluble en el marco del Estado actual, en tanto está llamado a preservar a toda costa la estructura ya agotada; por eso, también, ese conflicto por el que atraviesa en este momento la sociedad 
guatemalteca, y que se prevé de larga duración.

A ello se suma el contexto internacional, en el cual pesan la situación centroamericana y la política de EU hacia la misma, particularmente contra los movimientos de cambio social en el área. Estos son factores que sobredeterminan la situación de cada uno de nuestros países e incrementan la complejidad y las dificultades para la solución de sus respectivos conflictosinternos. Las recientes elecciones en Nicaragua son un ejemplo.

Así, pese al matiz que introdujeron en dicha situación la acción contrainsurgente iniciada después del golpe de Estado de 1982 y lá presencia del gobierno demócrata cristiano de Vinicio Cerezo Arévalo (1986-1991), más decuatro años de ejercicio gubernamental muestran que ni el gobierno ni el ejército ni la clase dominante tienen intención, ni pueden llevar a cabo, los cambios que requiere Guatemala. Es más, ni siquiera manifiestan que se pueda iniciar el camino que tales cambios requieren; este camino atraviesa por el reconocimiento y la aceptación de las fuerzas tradicionales, y de la participación política de las fuerzas emergentes en la gestión social.

Lo que interesa resaltar, por ahora, como apreciación de conjunto, es que la penetración, extensión y profundización de las relaciones capitalistas en el país y las transformaciones en la manera de producir acordes con el capitalismo han ido modificando, sobre todo a lo largo de los últimos 40 años, las bases tradicionales de la sociedad guatemalteca; y que estas transformaciones, sin embargo, no han podido encontrar un correlato-en el plano político-capaz de abrir perspectivas de solución para los graves problemas nacionales, pese a los intentos-básicamente hechos por el ejércitopara generar condiciones que rompan el enlazamiento histórico y le den viabilidad al desarrollo capitalista.

\section{LA ACTUAL APERTURA POLITICA}

En este contexto y luego del ascenso y reflujo revolucionarios de inicios de los años ochenta, el triunfo electoral del demócrata cristiano Vinicio CerezoArévalo, en noviembre de 1985, confirmó -para sorpresa de muchos-una tendencia que se venía perfilando desde mediados de 1984 con la elección de Asamblea Constituyente; en efecto, dentro de los planes contrainsurgentes, contenidos en el Plan Nacional de Seguridad y Desarrollo (PNSD), dado a conocer el 5 de abril de 1982, días después del golpe de Estado de ese año, la apertura política era una necesidad ineludible para el régimen.

De acuerdo con dichos planes, la apertura contribuiría a rescatar la imagen internacional del gobierno de Guatemala -rompiendo además lassimpatías y alianzas construidas a este nivel por el movimiento revolucionario- al tiempo que tendría efectos disgregantes sobre los revolucionarios los cuales, según estesupuesto, enfrentados enérgicamente en el plano militar; verían en la apertura política una posible salida a su dificil situación.

Adicionalmente -se pensaba-, el régimen recuperaría legitimidad y podría intentar el logro de una estabilidad a largo plazo, reactivar la economía y restañar las fricciones surgidas entre los gobernantes militares y la burguesía. Dichas fricciones se debieron, fundamentalmente, a los altos niveles de corrupción a que llegaron aquéllos, especialmente durante el gobiemo del general Romeo Lucas García (1978-82), atentando aun contra sectores dela burguesía y el propio sistema dominante, adicional a su mani-

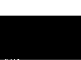


fiesta incapacidad para contener el ascenso de las luchas.

Se buscaba, también, la ayuda internacional y el logro de un clima propicio para la repatriación de capitales y el flujo de la inversión extranjera, así como generar paliativos para el descontento popular y anular la posibilidad de que el pueblo organizado viera en la revolución un camino; por el contrario -de acuerdo a estos supuestos-, aquél sería mediatizado y, en lo posible, ganado al respaldo, si no es que también a la defensa activa, del sistema dominante.

El ejército se proponía en lo fundamental, destruir el movimiento revolucionario y, sobre esa base, procurar una cierta estabilidad del Estado; a partir de ella se esperaba recuperar el crecimiento capitalista, que éste tuviera un respiro y que pudiera darse sin tantos sobresaltos, tal como ha sido el propósito de los sucesivos gobiemos contrarrevolucionarios desde 1954, aunque sin éxito.

De acuerdo con el PNSD, el paso inmediato era la destrucción del mojimiento revolucionario, entendiendo por ello que sus fuerzas dejaran de ser fuerzas revolucionarias, y abandonaran sus propósitos o se vieran imposibilitadas para impulsar su proyecto.

Para ello fue fundamental golpear a las organizaciones guerrilleras en sus reductos de la capital y la costa sur (1981) y, después, desarticular su base social, particularmente en el noroeste del país, con las campañas de genocidio y tierra arrasada de 1981 a 1983. No obstante, el golpe final no llegó.

De acuerdo con el PNSD, dicho golpe sería el resultado -entre otras acciones adicionales a las de orden militar- de la apertura política y la reactivación económica que, entre otras cosas, per-

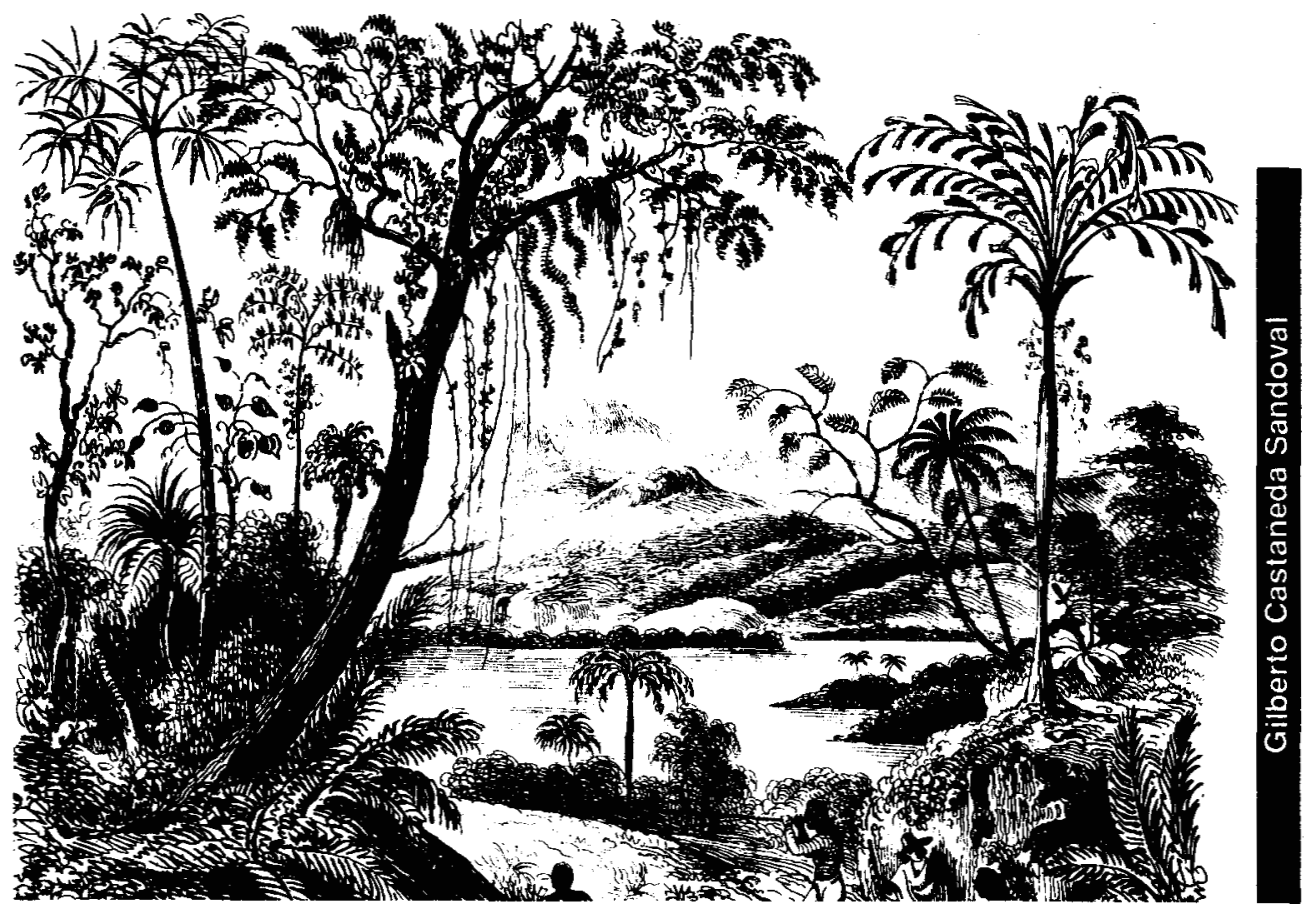


mitiría generar paliativos a la difícil situación que vive la inmensa mayoría de guatemaltecos. En ambos casos, y articulándose estrechamente entre sí, era importante la apertura politico-diplomática para lograr los apoyos que el desarrollo de esta compleja estrategia necesitaba.

En este contexto y como proyección del sentido histórico de las luchas guatemaltecas, aunque en ese momento se conjugaban con los planes contrainsurgentes, la participación de los votantes en las elecciones generales de 1985 y su opción mayoritaria por la Democracia Cristiana (DC), expresaron el rechazo generalizado de la población a los militares y al terrorismo estatal. Era una especie de "ruta alterna" dictada por las condiciones del que entonces era resultado, básicamente, de los golpes recibidos y del clima de negociación regional.

Sin embargo, y en tanto las contradicciones que resumen y explican la lucha en Guatemala no fueron modificadas, siguieron incubándose nuevos momentos de confrontación. Estas contradicciones se han vuelto todavía más agudas y dificiles de resolver ahora cuando los planes contrainsurgentes, al no alcanzar sus objetivos, aumentan los costos y los obstáculos que tiene el proceso de cambio social en Guatemala.

\section{LOS LÍMITES DE LA CONTRAINSURGENCIA}

Las dificultades que han tenido los planes contrainsurgentes son múltiples y atañen a cada uno de los aspectos que se propusieron resolver.

Así, por ejemplo, un factor que jugó en contra de sus previsiones politicas fue el hecho de que el ejército tuvo que pasar relativamente rápido a la fase de la apertura electoral sin haber logrado asentar las bases previas necesarias para ello, en particular, reducir la actividad guerrillera a una simple molestia como fue el propósito declarado por los militares.

Este paso se dio, por una parte, como resultado de la presión internacional y las negociaciones de paz regionales y, por otra , debido a la demanda interna de los partidos electorales y de la propia burguesía guatemalteca, recelosos de que el ejército quisiera ganar tiempo y mantener su presencia directa al frente del Estado. ${ }^{1}$

De esta manera, apresurando el proceso e incumpliendo supuestos básicos del PNSD, quedaron sentadas las bases de las actuales contra dicciones que dividen a los grupos de poder y de la imposibilidad que ha tenido el régimen para concretar sus objetivos. No era lo mismo pensar en una apertura política con la

${ }^{1}$ Baste recordar las tensiones que se dieron dentro de los sectores de poder durante el gobierno del general Efraín Ríos Montt (1982-83) y en parte con el gobiemo del general Humberto Mejía Victores (1983-86), ante lo que la totalidad de partidos políticos y las principales cámaras empresariales juzgaron como lentiud en el impulso de las elecciones prometidas luego del golpe de Estado. Baste recordar, también, cómo la transacción temporal que significó la constitución del Consejo de Estado a mediados de 1982, como órgano consultivo del presidente de la república, tuvo pocos efectos en el largo plazo. Desde luego, no eran aprehensiones gratuitas pues, en efecto, dentro del gobiemo militar de facto -que se extendió del 23 de marzo de 1982 al 14 de enero de 1986-, el mandatario castrense en turno concentraba en su persona las funciones ejecutiva $y$ legislativa (mediante decretos-leyes), así como la potestad de nombrar y remover a jueces y magistrados. Es claro pues que, si sumamos el mando militar que tenía, todoesto se traducía en un poder muy concentrado y muy grande que aparecía lesivo aun para los sectores dominantes. Por eso, en parte, el golpe de Estado de 1983 que derrocó a Ríos Montt y, por eso también, la relativa prontitud con la que su sucesor asumió la convocatoria a elecciones de Asamblea Nacional Constituyente, a mediados de 1984, y la fijación de las elecciones generales para noviembre de 1985.

\section{9}

9 
guerrilla en desbandada -como era el supuesto contrainsurgente-que con ésta en proceso de reactivación, recuperando condiciones que se suponían vulneradas y escenarios de lucha de los que había sido desalojada; tal es el caso de los departamentos centrales, en las proximidades de la capital guatemalteca.

Hay que considerar, además, que el actual apoyo social con que cuenta la guerrilla se da luego de la escalada represiva de $1981-83$, y que, por ello, hay una conciencia mayor por parte de quienes colaboran o se incorporan a ella.

Adicionalmente, sibien la contraofensiva militar generó fracturas dentro del movimiento revolucionario - por la lógica de las diversas concepciones que sobre lo que ocurría y el cómo enfrentarlo se dieron, junto a problemas en cuanto al tratamiento interno de estas divergencias-, esas fracturas no representaron el "traslado" de algunos de estos grupos hacia el terreno político planteado por el ejército sino, por el contrario, la apertura de nuevas posibilidades para la revolución.

Desde otro ángulo, tampoco la reactivación económica avanzó con la celeridad y en los términos previstos, y menos frente a la aceleración del proceso político y sus retos. Por ejemplo, adicional a la lentitud y a las dificultades que mostró la llegada del apoyo económico internacional, así como las dificultades para la reactivación de la inversión extranjera, tampoco los gobiernos militares -ni el de Vinicio Cerezo- lograron que la burguesía y los terratenientes dieran su aporte económico a la lucha contrainsurgente en los términos requeridos, por lo que los paliativos para el descontento popular, por ejemplo, tampoco llegaron.

Dicho apoyo fue planteado al menos de dos maneras: una, mediante una tí- mida reordenación tributaria-que fueviolentamente rechazada por las cámaras patronales - y dos, mediante el pago de un "bono de guerra" -que tampoco se hizo efectivo. De más está decir que tampoco se logró que los empresarios reiniciaran sus inversiones y repatriaran sus capitales, pese a la devaluación del quetzal cuya paridad con el dólar cayó en más de $300 \%$ en 1983 y ahora, de nuevo, en $50 \%$, deslizándose, desde finales de $1989 .^{2}$

En estas condiciones, otro supuesto de los planes castrenses, relacionado con la aceptación -y aun promoción- de la organización y movilización de los trabajadores y del pueblo en general como camino para crear condiciones para un consenso básico a favor del sistema dominante, tampoco avanzó, por una parte, por las carencias políticas dentro del bloque dominante $y$, por otra, por el tamaño del reto histórico, aunque también, por no contar con el complemento indispensable en el terreno económico. Así, la previsión contenida en el PNSD trajo más problemas que ventajas.

Por ejemplo, en junio de 1984, se formó el Grupo de Apoyo Mutuo (GAM) formado por familias de los detenidos-desaparecidos. Como más tarde lo harán otras agrupaciones similares, entre ellas el Consejo Nacional de Viudas de Guatemala (CONAVIGUA), la demanda central del GAM es la de que se investigue el caso de sus familiares asesinados o desaparecidos, se les informe de los resulta-

\footnotetext{
${ }^{2}$ Desde luego, no era una respuesta inesperada si se toma en cuenta que, históricamente, el empresariadoguatemaltecosiempre ha exigidocomo prerrequisito que haya "condiciones favorables para la inversión" -estabilidad política y social por ejemplo-y nunca ha estado en su ánimo el involucrar sus capitales en la promoción de un proyecto nacional tan riesgoso, complejo y dificil como el que necesariamente se configura en la situación guatemalteca.
} 
dos de las investigaciones y se castigue a los responsables. La demanda, procedente y del todo justa, no se sale de los marcos constitucionales -es más, los refüerza-, pero en las condiciones de Guatemala atenta contra uno de los pilares del régimen: el ejército.

Por igual y desde otro ángulo, ante la rearticulación sindical y las demandas salariales generalizadas, el gobierno no tiene fondos suficientes para satisfacerlas ni tiene capacidad para lograr que los patronos flexibilicen sus posiciones, tradicionalmente renuentes a satisfacer esas demandas. En este terreno, una barrera adicional son los problemas económicos del país y los compromisos adquiridos con el capital financiero internacional (básicamente el FMI y el BM) según los cuales se debe reducir el gasto estatal y sobre todo el de funcionamiento (se entiende por ello la inversión social del Estado: salud, vivienda, bienestar, etc.). Desde luego, en estas condiciones tampoco puede pensarse en abatir el enorme desempleo y subempleo existentes, superiores a 50\% de la PEA.

Sin embargo, esto no es todo. A ello se suma la ejecutoria gubernamental de la $D C$.

Desde un primer momento la opción básica de la DC fue granjearse el apoyo del ejército-como garantía de su permanencia y continuidad en el gobierno-y lograr la aceptación y comprensión de la burguesía y de los terratenientes para su gestión y, de ser posible, su colaboración directa. Cerezo Arévalo no pretendió ni se propuso capitalizar el apoyo electoral obtenido en las urnas, pues ello le habría representado condicionamientos por parte de los sectores populares, dificiles de aceptar por los empresarios y los mandos militares. -De hecho, la DC renunció explícitamente a sus planteamientos electorales queleganaron el voto popular en 1974, en los que contemplaba la reforma agraria.

En la práctica, tal como se habría podido pronosticar a la luz de una lectura atenta de la historia guatemalteca, tales decisiones resultaron contraproducentes. Sibien, en efecto, el ejército-al menos su alto mando encabezado por el actual ministro de la Defensa, general Alejandro Gramajo-, ha resultado hasta ahora garantía suficiente para la permanencia del gobierno, la dificultad para ganar la aceptación y comprensión de la burguesía y los terratenientes alienó la posibilidad de un apoyo popular para el gobierno. Por ello, Cerezo no pudo cumplir con esta parte de los planes contrainsurgentes, contribuyendo así a los conflictos que se vienen desarrollando dentro delossectores dominantes y el propio ejército, como veremos más adelante. ${ }^{3}$

A esto se suman la corrupción gubernamental, los desaciertos y la incapacidad de la administración para la ejecución de planes y programas y su dispendio de las finanzas públicas, así como la pretensión de la DC de lograr a toda costa una "era demócrata cristiana" a la cabeza del Estado. Además, el presidente Cerezo asume actitudes prepotentes, centralizadoras de toda la actividad política de su gobierno y, adicional a sus frivolidades y a una cierta "pose" ajena a sus ahora evidentes insuficiencias para ejer-

\footnotetext{
${ }^{3}$ Por ejemplo, los empresarios guatemaltecos se opusieron y bloquearon la posibilidad de echar a andar, en 1988, el llamado "pago de la deuda social" previsto en el "Proyecto Nacional" demócrata cristiano, derivando -por ése y otros motivos-en el intento golpista del 10 de mayo de ese año. Tal como lo señalara recientemente el arzobispo metropolitano, monseñor Próspero Penados, son sectores "que no quieren cambiar y persisten en la explotación y cuando se habla de mejores salarios y mejores prestaciones dicen que uno es comunista".
} 
cer el mando del pais, se ha empecinado en imponer como candidato a la presidencia a su amigo y correligionario Alfonso Cabrera, llevando a la fractura al partido demócrata cristiano.

De esta manera, el problema se ha hecho más grave y el rechazo al gobierno de importantes sectores patronales y mandos castrenses va en aumento. No hay que olvidar que la $\mathrm{DC}$ es vista por más de un círculo de poder como "socializante" y que-pese a todos sus intentos de concertación con los empresarios-es vista por éstos como partido opositor. ${ }^{4}$

En este proceso, la imagen y posibilidades de Cerezo como presidentese han debilitado y el presidente ha pasado a una especie de "toma de distancia" del acontecer nacional -que no internacional necesariamente-, inconcebible en un mandatario. Algo asi como lo que ocurrió a finales de su periodo presidencial al también abogado Julio César Méndez Montenegro (1966-70), para quien lo importante fue finalizar su mandato $y$ hacer el traspaso "constitucional" al nuevo presidente electo, considerando este hecho como "su aporte a la democracia" sin importar las condiciones. Al final, este fue el inicio de la sucesión ininterrumpida de gobiernos militares iniciada en 1970 y finalizada en 1986. Ahora, los candida-

\footnotetext{
${ }^{4}$ En efecto, durante las elecciones generales de 1974, salió triunfadora la alianza DC-FUR (Frente Unido de la Revolución, socialdemócrata), pero fueron despojados mediante un escandaloso fraude, debido entre otras razones a la propuesta que hizo dicha alianza, de una reforma agraria, la cual fue rechazada enérgicamente por los terratenientes y la burguesía. Igualmente, dichos sectores de poder no olvidan que mucha de la base social de la DC-como del FUR y del Partido Socialista Democrático (PSD)- se sumó a finales de los años setenta al movimiento revolucionario en ascenso, en momentos en que el terror estatal los golpeaba, junto a cristianos, campesinos indigenas y dirigentes populares, entre otros.
}

tos militares vuelven a aparecer como espejismos dentro del panorama electoral. 5

Porúltimo, está la cuestión de la apertura político-diplomática. Si bien, como ya se dijo, el Estado guatemalteco recuperó nexos internacionales y mejoró su imagen, ello no se tradujo en los apoyos previstos, posiblemente con la clara excepción del sostén proporcionado por la AID norteamericana. Pero, además, se dio un cambio importante en la situación regional a partir de agosto de 1987. El 7 de ese mes, el proceso negociador dio un vuelco al pasar de los planteamientos del Grupo de Contadora a los compromisos presidenciales de Esquipulas II.

Si se hace un análisis de las negociaciones de Contadora podrá encontrarse que las mismas comprometían poco al régimen guatemalteco, al circunscribirse en lo fundamental a la confrontación interestatal existente, básicamente entre Nicaragua-Costa Rica y NicaraguaHonduras. Por el contrario, los acuerdos de Esquipulas II, al asumir los factores internos del conflicto, colocaron al gobierno guatemalteco en la necesidad de responder en términos de reconciliación nacional, cese del fuego y democratización, entre otros, lo que significó que perdiera la posición negociadora "desde fuera" -que venía manteniendo desde inicios de 1985-y pasara a una posición negociadora "desde dentro", es decir, como parte del conflicto centroamericano y no de su solución.

Este cambio de términos ha tenido costos para el régimen guatemalteco sin obtener todos los beneficios esperados.

${ }^{5}$ Así se lo expresó a Charles Lane, del Newsweek, el presidente de la Corte Suprema de Justicia, Edmundo Vásquez Martínez: "Cuando hay inseguridad, algunos claman por la seguridad, aún si esto significa el mandato por la fuerza." 

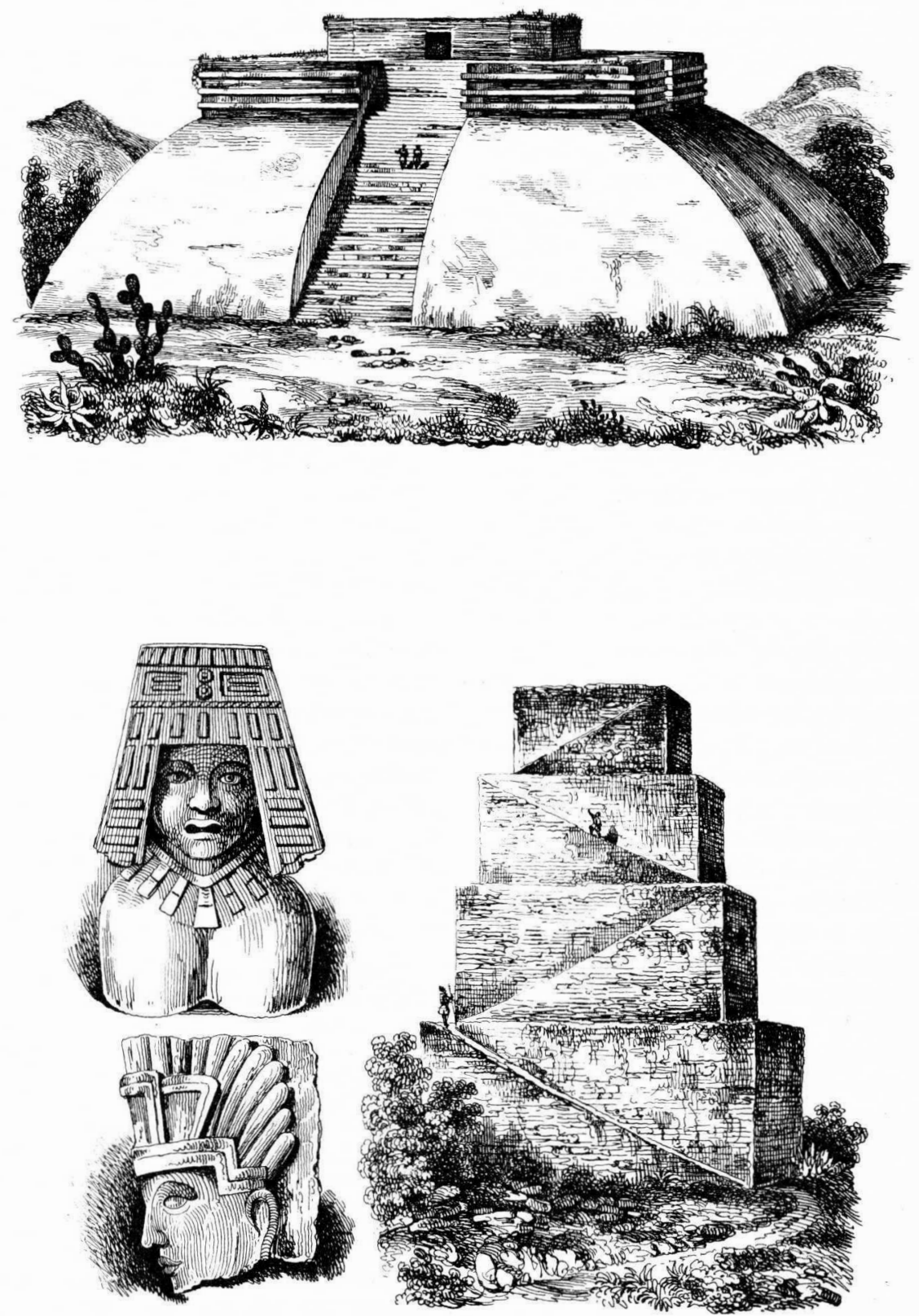
Por ejemplo, a partir de ese momento fue dificil para el gobierno de Cerezo negarse a conversar con la guerrilla guatemalteca, situación que derivó en las conversaciones de Madrid, en octubre de 1987. El efecto inmediato fue el rechazo de dichas pláticas por parte de los sectores reaccionarios del país-civiles y militares- y un clima de confrontación que, alimentando otras contradicciones ya existentes dentro de los grupos de poder, derivaron en el inicio -a finales de 1987- del ciclo de intentos de golpes de Estado que aún no termina.

LAS PUGNAS INTERNAS EN LOS SECTORES DE PODER

En este contexto, un elemento clave son las pugnas dentro de los sectores de poder. Una cosa es estar de acuerdo con el PNSD -tal como parecía que habría de desarrollarse- y otra es enfrentar los resultados concretos del mismo. Si la guerrilla se mantiene y además aprovecha las posibilidades de lucha política existentes; si el movimiento sindical y popular no es cooptado o mediatizado como se esperaba y, por el contrario, muestra niveles importantes de combatividad ${ }^{6}$ y asume demandas en materia de derechos humanos que atentan contra el ejército; si la presión internacional obliga a mantener este juego peligroso de la apertura política cuando sería mejor abandonarlo; si dentro del ejército aparecen pugnas adicionales por la actividad politica en su seno y la pérdida de la disciplina jerárquica -como ocurrió durante

\footnotetext{
${ }^{6}$ Cito, por ejemplo, los casos de la huelga de la costa sur a inicios y finales de 1989 y de la huelga magisterial y la de varios sectores de empleados estatales a mediados del mismo año.
}

el mandato de Ríos Montt-;; entonces, los enfrentamientos aparecen.

Además, estos enfrentamientosse multiplican cuando a los resquemores de la clase dominante por la conducción que el ejército hizo del Estado -principalmente en el periodo de Lucas García-y su desconfianza ante las pretensiones de poder de los altos oficiales, se suman realidades inocultables como las derrotas electorales de los partidos de ultraderecba (el Movimiento de Liberación Nacional, MLN, y la Central Auténtica Nacionalista CAN, entre otros) y su desplazamiento por posiciones "centristas" (la Unión del Centro Nacional, UCN, por ejemplo) o "socializantes" (la DC, al decir de muchos empresarios), bajo el cobijo -O al menos el aliento- de sectores del ejército.

Igual aumentan los enfrentamientos cuando, pese al evidente peso político del ejército dentro del país, se necesita recuperar la disciplina jerárquica dentro del mismo, lo cual conllevaría, de aplicarse estrictamente, a que sólo hicieran política sus mandos superiores. A esto se suma el hecho de que sean los mandos medios e inferiores los que soportan la carga directa de la guerra, mientras la alta jerarquía militar la dirige desde sus escritorios. Finalmente y sin agotar la lis-

\footnotetext{
${ }^{7}$ En efecto, el golpe de Estado de abril de 1982 fue encabezado por jóvenes oficiales descontentos con Lucas García y, aunque promovieron la constitución de una Junta Militar de Gobierno encabezada por dos generales y un coronel, al final, en junio siguiente, contribuyeron al desplazamiento de dicha Junta por parte de uno de sus integrantes (el general Efraín Rios Montt), quien se constituyó en presidente y nombró una junta asesora entre dichos jóvenes oficiales, los cuales -en la práctica-pasaron a conducir al gobierno y al ejército. En buena medida, el desplazamiento de Ríos Montt mediante el golpe de-Estado de agosto de 1983 tuvo, entre otras, esta causa.
} 


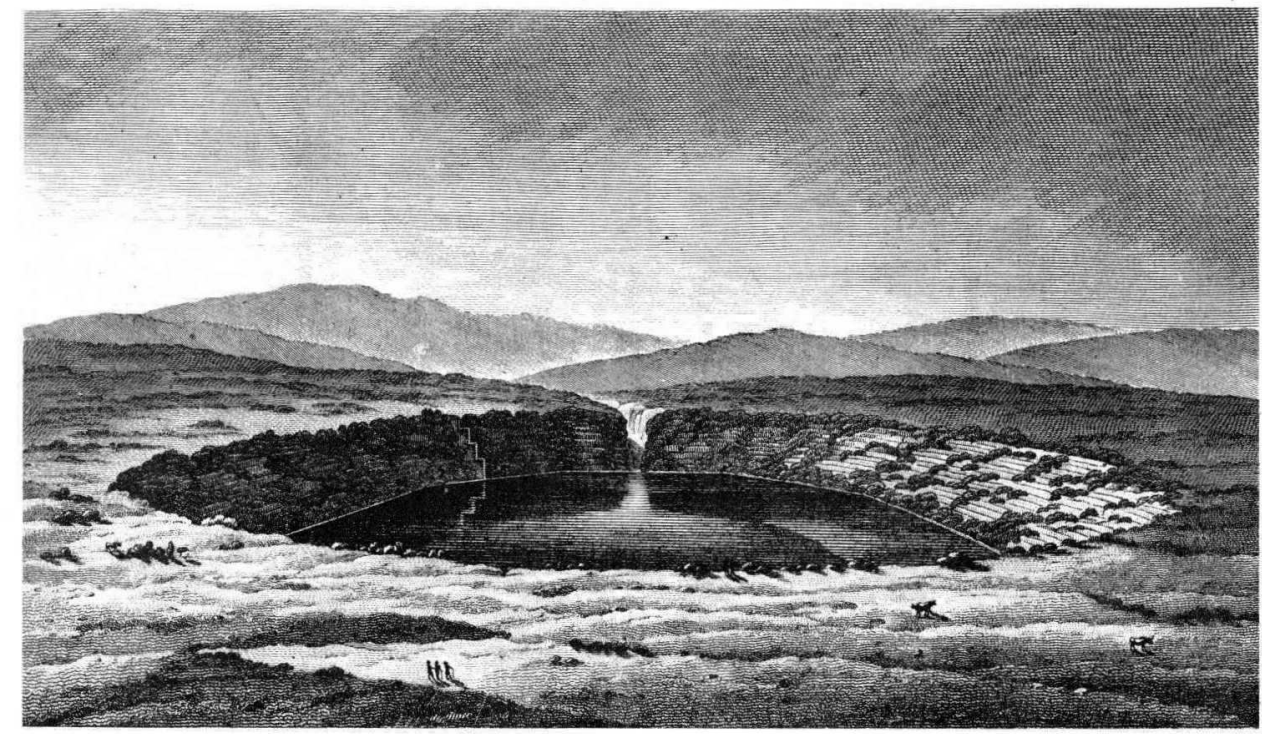

ta, es este alto mando el que concentra y usufructúa las ventajas de dicho ejercicio político y de las oportunidades de hacer negocios -lícitos o no- al cobijo de la administración estatal, pero es un alto mando que no comparte los beneficios con sus subordinados ni deja prosperar sus iniciativas de enriquecimiento. Así ocurrió, por ejemplo, con la auditoría interna al ejército ordenada por el general Gramajo a inicios de 1989 y que tuvo severas repercusiones aún en términos de la intentona de golpe de Estado del 9 de mayo de ese año. ${ }^{8}$

${ }^{8}$ Por ejemplo, dicha auditoría generó medidas disciplinarias importantes dentro de la Fuerza Aérea Guatemalteca (FAG), incluida la destitución de su comandante el general Enrique Wohlers. No es ocioso recordar que el agrupamiento táctico de la FAG jugó un papel importante en la intentona militar mencionada.
Por todo eso, no es difícil suponer la existencia de los llamados "Oficiales de la Montaña" opuestos a la alta burocracia militar que, al parecer, han jugado un papel preponderante en dichas intentonas golpistas.

Estas contradicciones se acrecientan cuando, como ya se dijo, al tiempo que se mantiene el esfuerzo de guerra, se impulsan procesos políticos para el cese al fuego y el diálogo nacional y el experimento aperturista no da algunos de los resultados previstos, como lo sería un incremento sensible de la ayuda militar.

De esta manera, para los sectores civiles y militares desafectos con la marcha de los acontecimientos, resulta absurdo y contrario a sus intereses las reiteraciones del general Gramajo sobre la necesidad de la apertura politica. "Es necesario que en este momento en que estamos saliendo del oscurantismo ideo- 


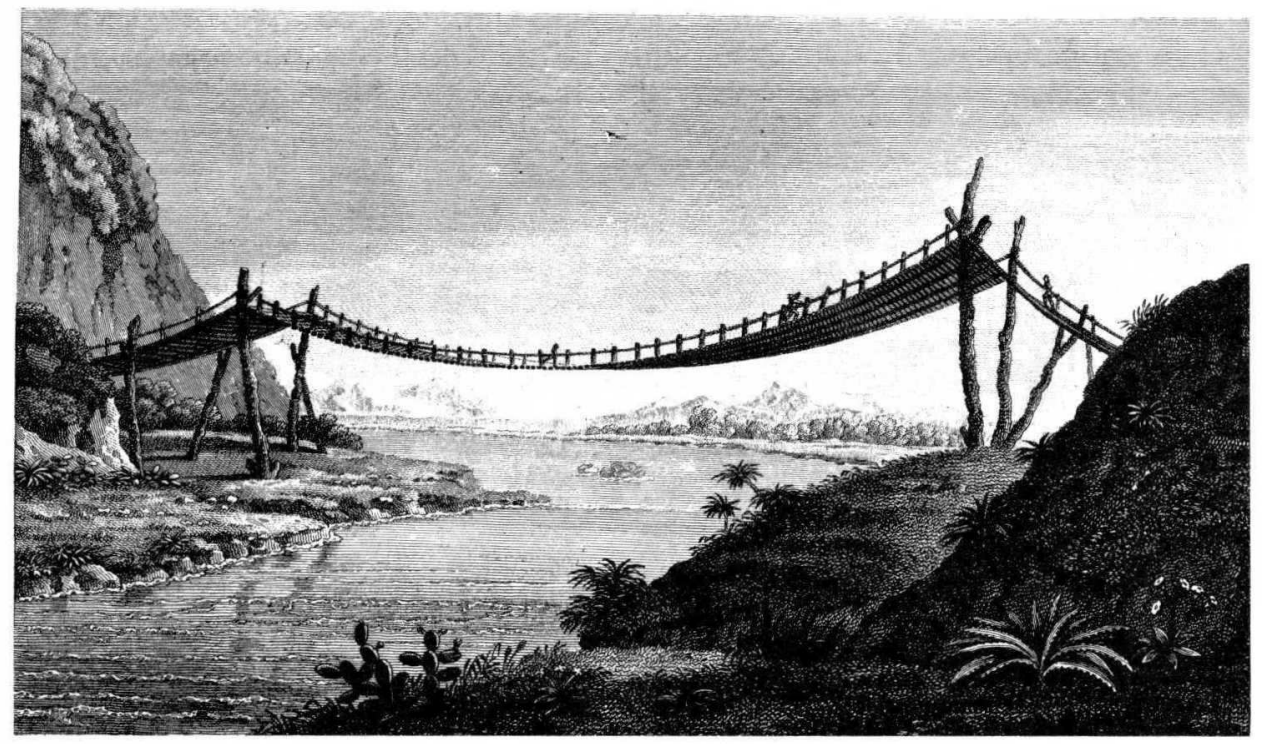

lógico -dijo en el discurso conmemorativo del 188 aniversario del ejército de Guatemala, el 30 de junio del año pasado-, dejemos también por un lado la intolerancia política, que dejemos de ver el mundo en forma bipolar y que pensemos que si no consolidamos este proceso por medio del fortalecimiento del cuerpo político y la organización del cuerpo social, jamás saldremos del subdesarrollo en todos los campos."

No obstante, hay dos elementos que aglutinan a los sectores de poder: la de-

\footnotetext{
${ }^{9}$ Desde otroángulo de preocupación, es claro que un problema que confronta Guatemala son las carencias que existen dentro de este "cuerpo político", las cuales le impiden funcionar -efectivamente-como mediador entre el cuerpo social y el Estado. Baste decir que el Partido Socialista Democrático (PSD) apoya ahora la candidatura presidencial de René de Léón Schlotter, demócrata cristianode viejocuño, contendiente derrotado por la nominación presidencial de la DC (que le fue asignada a Carlos Cabrera), además de ser reconocido como político de ideas conservadoras.
}

fensa del sistema y el recuerdo del ascenso revolucionario de inicios de los años ochenta, cuando vieron cercana la posibilidad de su derrumbe. En efecto, aunque divididos por sus pugnas internas, no están dispuestos a dejar que las cosas lleguen a los niveles que adquirieron entonces y esto les da unidad de fondo, al tiempo que estimula su tendencia al uso directo de la fuerza a la menor señal de peligro.

Es cierto que el movimiento popular $y$ democrático está en un proceso lento y dificil de rearticulación; que el movimiento revolucionario aún no recupera la capacidad de influencia política nacional e internacional que antes tenía -aunque avanza en ello-; que las pruebas de fuerza que hasta ahora han dado las organizaciones sindicales y populares y la guerrilla no ponen en peligro al sistema (huelgas, movilizaciones y formas unitarias de organización, en el primer caso; incremento de la capacidad militar, 
presencia en territorios de donde fue desalojada e impulso de una política que plantea el diálogo con el gobierno a fin de buscarle solución política al conflicto armado interno, en el segundo caso). Sin embargo, nadie puede ignorar que todas estas acciones ocurren luego de un periodo en que el terrorismo de estado se empleó a fondo, buscando derrotar toda perspectiva revolucionaria.

Por eso, desde la óptica de sus intereses, la necesidad de la represión es mayor y más inmediata que antes, aunque ello traiga dificultades para generar estabilidad de largo plazo y acceder a formas consensuales de dominación en las que, por ejemplo, los procesos electorales jueguen un papel central.

Un análisis detenido de los intentos golpistas -sobre todo el del 10 de mayo de 1988 y el del 9 de mayo de 1989arroja elementos que permiten señalar que la naturaleza y el tipo de las divergencias entre los sectores de poder no tocan el fondo de esta coincidencia fundamental. Estas divergencias no riñen con el mantenimiento $-y$ aun con el ascenso- de la represión. ${ }^{10}$

${ }^{10}$ Así lo evidencian el sostenimiento de la misma en el campodurante todos estos años de "apertura", la vuelta a las matanzas -desde finales de 1987-yla escalada represiva en la capital de agostoseptiembre del año pasado. Dentro de la misma fueron asesinados dirigentes populares como José de la Cruz, del Sindicato de Trabajadores del Instituto Nacional de Electrificación (sTINDE), y Romualda Camey del GAM, de las familias de los detenidos-desaparecidos; al mismo tiempofueron secuestrados once dirigentes estudiantiles universitarios (siete de ellos aparecieron posteriormente asesinados luego de crueles torturas). La forma en que se dieron estos hechos y el evidente propósito que hubo en el caso de los estudiantes de hacer público el crimen, se enmarca dentro de la lógica de la represión preventiva a que hacemos referencia, cuyos efectos van dirigidos no sólo a la víctima (obtención de información, por ejemplo) y a la
Por eso la congruencia que existe -desde el punto de vista de la contrainsurgencia- entre apertura politica y represión y, también, la dificultad para que las elecciones sean, efectivamente, un camino para alcanzar la democracia en Guatemala. ${ }^{11}$

\section{ALGUNAS CONSIDERACIONES FINALES}

Así las cosas, el PNSD que según el general Gramajo se encaminaba en 1988 de la "seguridad y el desarrollo" hacia la "estabilidad y el bienestar", se quedó en sus prolegómenos y lo que ahora existe es una disputa dentro de los sectores de poder sobre el camino a seguir. Esto le agrega dificultades y le da mayor complejidad al "tránsito a la democracia" planteado en el PNSD y hace más preocupante la perspectiva del país.

En efecto, ante las insu ficiencias todavía no superadas del movimiento popular y revolucionario, los grandes beneficiados de esta situación son -al menos en la coyuntura-, los sectoresultraderechistas que no sólo sacan partido de sus presiones golpistas sino que, además, al margen de que puedan lograrlo, buscan repetir la experiencia salvadoreña de una DC arrinconada y sin iniciativa que facilitó o no pudo impedir, el ascenso de ARENA

desarticulación de la organización en que ella participa, sino que alcanza a estratos diversos de la población. Ahora, basta una amenaza telefónica, por ejemplo, para que cualquier luchador social se sienta en peligro, lo que afecta sus posibilidades de acción; algunos saldránal exilio, como ya está ocurriendo.

${ }^{11}$ El general Gramajo es muy claro al respecto cuando califica la relación apertura política-represión como una cuestión complicada en la que "se gradúa más la aplicación de la coerción, se gradúa más la aplicación de los medios que tienen las fuerzas armadas para imponer la paz, en otras palabras, la aplicación de la violencia es gradual". 


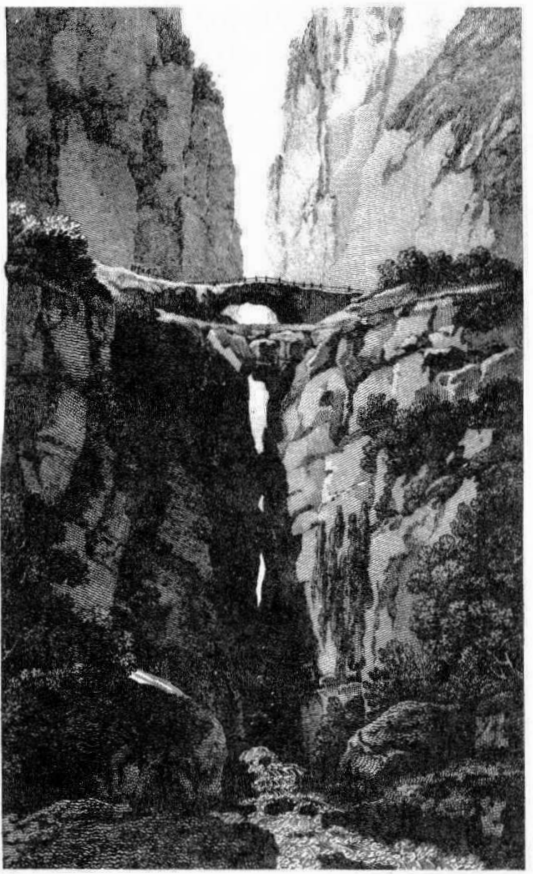

al gobierno, con todo y las reservas que al respecto tenía EU.

En efecto, el que no existan espacios democráticos, que el régimen esté acosado por múltiples problemas y existan importantes contradicciones dentro de los sectores dominantes no lleva mecánicamente a un nuevo auge revolucionario. La realidad no oscila como un péndulo; es algo más complejo que esto. Barbarie y civilización no son, necesariamente, extremos alternos y no es cuestión simplemente de escoger una u otra opción. En ciertos casos y bajo determinadas circunstancias lo que se puede dar es una descomposición paulatina y creciente del tejido social, como ya parece estar ocurriendo en Guatemala.

La sociedad se revitaliza por la fuerza de sus conglomerados, por sus niveles de organización, por su capacidad de movilización en torno a objetivos comu- nes, por lo que quien se proponga resolver la actual situación guatemalteca no sólo necesita de la simpatía y del apoyo de la población, de cuadros y bases organizados, de una propuesta de futuro coherente y realista, sino que necesita además y de manera importante, aislar lo principal de quienes defienden el estado de cosas imperante y se oponen al cambio que se necesita. Para ello se requiere de la solidez que deriva deuna formación y una experiencia políticas que no es fácil de lograr en países como los nuestros donde el costo de la explotación y la dominación de siglos es muy alto y se refleja de manera particularmente negativa en relación con estos aspectos.

Tal como se señala en otra parte, ${ }^{12}$ la actual experiencia bajo el gobierno de la DC muestra que la cuestión clave para salir de esta situación está en la naturaleza del poder (al servicio de quien esté), y en consecuencia, en la capacidad que este poder tenga para subordinar a los intereses mayoritarios a una clase dominante que no permite cambio alguno en un país que los reclama cada vez con más urgencia y cuyo pueblo ha pagado ya un elevado precio.

El obstáculo fundamental en esta dirección es la continuidad del poder de esa clase dominante que se conformó desde la colonia y se ha renovado y ampliado pero sin modificarse en lo esencial, que si lo ha hecho es para explotar más y que sigue siendo incapaz de impulsar un proyecto nacional al menos medianamente compartido. Pero esa tarea, a la luz que el análisis histórico nos ofrece, no es posible de ser cumplida por los actuales actores políticos -con el ejército como eje de ellos-pues requiere

${ }^{12}$ Centro de Estudios de la Realidad Guatemalteca (CERG), "Cambio y crisis social", en colección Temas, núms. 5-6, diciembre de 1988, pp. 22-23. 
una gran alianza nacional que ellos han demostrado no poder lograr. Se trata de una alianza que tenga por eje dicho objetivo -contrario a los intereses dominantes-y como espina dorsal la unidad -en el caso de Guatemala- de los trabajadores asalariados del campo y de la ciudad, de los campesinos pobres y de los pueblos indígenas, constituidos a estas alturas en importantes fuerzas políticas emergentes.

La cuestión fundamental estriba en la necesidad de que a partir de dicho poderse construya una democracia capaz de superar los obstáculos y las ataduras que se anudaron y perpetuaron a partir de 1954. En otras palabras, que a partir de ese poder se pueda construir una sociedad democrática realmente independiente. Una sociedad en la que haya libertad de organización y movilización y en la que los ciudadanos puedan plantear $y$ luchar por sus ideas $y$ proyectos; donde disentir no sea delito y donde defenderlos derechosno sea motivo para la persecución, la muerte o el desarraigo. Una sociedad, en fin, que no se subordine a los intereses externos y que conviva con otros pueblos sobre la base del respeto mutuo y la búsqueda con junta del bienestar común.

Sabemos, desde luego, que no es posible alcanzar esa sociedad de un día para otro, que el logro de la democracia y su correlato indispensable, el ejercicio dela independencia nacional, requieren de procesos más o menos largos y complejos, pero que lo importante es iniciar el camino.

Por eso, tal como lo propuso el Foro de Guatemaltecos Democráticos ante el Diálogo Nacional realizado en Guatemala, ${ }^{13}$ hay que partir de que la com-

13 Véase la ponencia presentada por el foro ante el Diálogo Nacional titulada "La democracia plejidad de la situación guatemalteca requiere de soluciones políticas inmediatas, de medidas sociales y económicas a corto plazo y de transformaciones profundas e ineludibles en el largo plazo; que es necesario que -sobre la base del consenso- se impulsen como mínimo cambios de estructuras anacrónicas como la agraria, la tributaria y del comercio exterior, que se redefinan las políticas económicas y los programas de acción social del Estado y, también, que se logren fórmulas de participación efectiva del pueblo organizado en la gestión social, particularmente de las comunidades indigenas, siempre discriminadas.

En definitiva -dice el Foro-, se trata de concebir la democracia como medio y como proceso para cambiar las injustas estructuras de la sociedad a partir del derecho de las mayorías nacionales. Esto pasa, en lo inmediato, por el logro de la vigencia plena del estado de derecho, que cese la represión y se disuelvan los grupos paramilitares clandestinos, así como el impulso de acciones que conduzcan al cese del fuego y a la solución política del conflicto armado interno y-a partir de ello-al inicio de un camino que lleve a la soluciôn de la problemática que está en el fondo de la confrontación social.

Sólo mediante un proceso de esta naturaleza, de garantía a los derechos humanos fundamentales, será posible -concluye el foro-el surgimiento de un gobierno que, sustentado en el apoyo del pueblo organizado, pueda remontar los obstáculos que los sectores tradicionales de poder oponen a los cambios que requiere con urgencia el país y sólo así -agrego ahora- los proceso electoralestendrán algún sentidoen Guatemala.

que necesitamos y el camino que proponemos para alcanzarla", abril de 1989. 


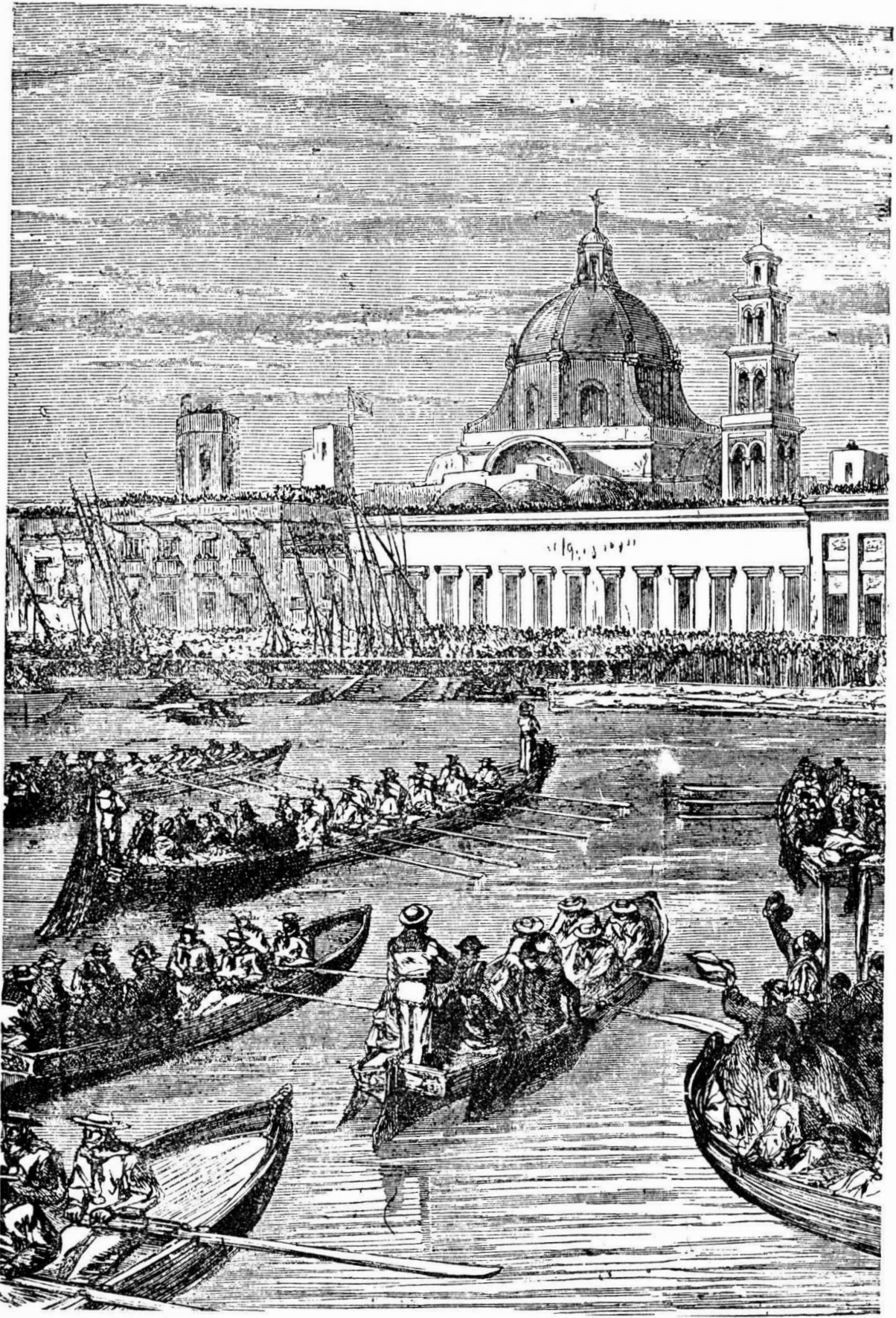

